\title{
PENGERING BERPENUKAR KALOR DENGAN SUMBER ENERGI SEKAM PADI
}

\author{
Ida Bagus Alit ${ }^{1}$, I Gede Bawa Susana ${ }^{2}$ \\ ${ }^{1,2}$ Jurusan Teknik Mesin, Fakultas Teknik, Universities Mataram \\ Jl. Majapahit No. 62 Mataram-NTB, 83125 \\ 2E-mail: gedebawa@unram.ac.id
}

\begin{abstract}
Abstrak
Pengeringan merupakan salah satu cara untuk memperpanjang masa simpan produk-produk pertanian. Proses pengeringan dapat dilakukan dengan cara konvensional maupun menggunakan alat pengering. Penggunaan alat pengering dapat dilakukan dengan memanfaatkan energi surya maupun sumber energi lain. Kelemahan pengeringan konvensional adalah sangat bergantung pada cuaca, sementara kelemahan alat pengering dengan sumber energi lain seperti energi listrik dan bahan bakar adalah diperlukannya biaya tambahan untuk sumber energi yang digunakan. Untuk itu diperlukan alat pengering dengan sumber energi yang lebih murah, seperti penggunaan limbah sekam. Di samping murah, limbah sekam juga mudah diperoleh. Penelitian ini mengkaji penggunaan alat pengering berbahan bakar limbah sekam padi untuk pengeringan cabai. Alat yang dirancang terdiri dari tungku pembakaran sekam, pipa penukar kalor dan lemari pengering. Penggunaan pipa penukar kalor bertujuan agar produk yang dikeringkan tidak terkontaminasi pembakaran sekam. Hasil penelitian menunjukkan berat bahan, kadar air, laju pengeringgan, dan efisiensi pengering mengalami penurunan terhadap waktu. Temperatur lemari pengering berkisar 50- $600 \mathrm{C}$, dengan laju aliran udara $0,49 \mathrm{~m} 3 / \mathrm{menit}$. Alat ini mampu menurunkan kadar air cabai 85,8\% hingga 58,2\% dalam jangka waktu 900 menit, dengan efisiensi rata-rata sebesar $22 \%$.
\end{abstract}

Kata kunci: Pengering, sekam, pengeringan cabai, penukar kalor

\begin{abstract}
Drying is one way to extend the shelf life of agricultural products. The drying process can be done by using conventional methods or a dryer. Dryer could utilize solar energy and others. The disadvantage of conventional drying by using solar energy is that very dependent on weather, while dryer with other energy sources such as electricity and fuel need an additional cost. For this reason, dryer with cheaper energy sources was needed, such as the use of husk waste. In addition to cheap, husk waste was also obtained easily. This study examined the use of dryer using rice husk waste for drying chili. The tool designed consists of husk burning furnaces, heat exchanger pipes and drying cabinets. A heat exchanger pipe is intended so that dry products were not contaminated with burning husks. The results showed that material weight, water content, crushing rate and drying efficiency decreased with time. The temperature of the drying cabinet ranges from 50 to $600 \mathrm{C}$ with an air flow rate of 0.49 $\mathrm{m} 3 / \mathrm{min}$. this tool can reduce chili water content $85.8 \%$ to $58.2 \%$ in 900 minutes, with an average efficiency of $22 \%$.
\end{abstract}

Keywords: Dryers, rice husks, chilies drying, heat exchangers

lama. Pengeringan alami merupakan pengeringan yang bergantung pada cuaca yaitu dengan cara

\section{PENDAHULUAN}

Salah satu cara untuk memperpanjang umur suatu bahan yaitu dengan melakukan proses pengeringan. Pengeringan merupakan cara untuk menghilangkan sebagian besar air dari zat padat dengan bantuan panas, baik secara alami maupun buatan [1], karena jika tidak dilakukan proses pengeringan maka bahan akan mudah rusak akibat adanya aktifitas mikroba dan jamur yang dapat merusak bahan, sehingga bahan tidak dapat bertahan penjemuran di bawah sinar matahari. Jika cuaca tidak memungkinkan maka proses pengeringan akan berlangsung tidak sempurna dan memerlukan waktu yang cukup lama. Teknis penjemuran yang biasa dilakukan oleh masyarakat yaitu dilakukan pada lantai jemur, alas anyaman bambu, tikar, atau dengan cara digantung. Kelemahan dari pengeringan dengan cara penjemuran diantaranya mudah terkontaminasi, sulit dikontrol, memerlukan tempat yang luas, dan memerlukan waktu yang lama [2]. Pengeringan buatan merupakan alternatif pengeringan yang dapat

1 Alit, Ida Bagus., dkk; Pengering Berpenukar Kalor Dengan Sumber Energi Sekam Padi 
dilakukan tanpa bergantung pada cuaca yaitu menggunakan alat mekanis atau pengering buatan. Pengeringan buatan menggunakan tambahan panas untuk mengatasi kekurangan pengeringan dengan penjemuran. Pengeringan mekanis memerlukan energi untuk memanaskan bahan, menguapkan air bahan serta menggerakkan udara [3]. Beberapa keuntungan yang didapat diantaranya kapasitas pengering dapat dipilih sesuai dengan yang diperlukan, tidak memerlukan tempat yang luas, serta kondisi pengeringan dapat dikontrol. Salah satu kendala yang dihadapi oleh masyarakat dalam menerapkan pengeringan buatan yaitu memerlukan investasi awal yang cukup besar.

Penelitian mengenai penggunaan alat pengering dan penggunaan sumber energi biomassa telah banyak dilakukan. Seperti Moharaj dan Candra melakukan penelitian tentang performa pengering tenaga surya konveksi paksa untuk mengeringkan cabai. Sistem yang dibuat terdiri dari kolektor surya plat datar, blower sentrifugal dan rak pengering. Blower mengalirkan udara dengan laju aliran udara sebesar $0.25 \mathrm{~kg} / \mathrm{s}$. Efisiensi alat pengering yang dirancang adalah sebesar $21 \%$ [4]. Pengeringan ikan teri menggunakan biomassa sabut kelapa melalui metode konversi energi menggunakan heat exchanger dengan sistem konveksi paksa menghasilkan peningkatan produktivitas perajin sebesar 54,88\% [5]. Proses pengeringan cabai merah dari kadar air $80 \%$ sampai $10 \%$ telah dilakukan menggunakan alat pengering tenaga surya. Waktu yang dibutuhkan untuk pengeringan tersebut adalah 33 jam dengan rata-rata intensitas matahari sebesar $420 \mathrm{~W} / \mathrm{m}^{2}$ dan laju aliran udara sebesar $0,07 \mathrm{~kg} / \mathrm{s}$, efisiensi sistem pengeringan diperoleh sebesar $13 \%$ [6]. Hasil pengujian alat pengering berpenukar kalor dengan bahan bakar sekam padi dilakukan untuk mengeringkan jagung dari kadar air $19 \%$ menjadi $12 \%$ membutuhkan waktu 47 menit untuk kecepatan udara $3 \mathrm{~m} / \mathrm{s}$ [7]. Fathurrahman dkk. melakukan penelitian pengaruh temperatur dan kecepatan udara terhadap laju pengeringan jagung pada alat fluidized bed dryer [8]. Dari penelitian ini dapat disimpulkan bahwa semakin tinggi kecepatan udara dan temperatur, waktu pengeringan jagung semakin cepat. Variasi kecepatan udara dan temperatur udara yang paling cepat mengeringkan bahan pada kecepatan udara $7 \mathrm{~m} / \mathrm{s}$ dan temperatur $65^{\circ} \mathrm{C}$ dengan massa bahan $0,5 \mathrm{~kg}$. Waktu yang dibutuhkan untuk mencapai kadar air $12,6 \%$ yaitu 30 menit.

Proses pengeringan baik menggunakan sumber energi biomassa maupun surya dengan konversi energi termal meningkatkan temperatur ruang pengering untuk mengeringkan bahan pangan. Rerata temperatur ruang pengering tanpa beban dapat mencapai $71,10^{\circ} \mathrm{C}$ [9] dan temperatur tertinggi $109,2^{\circ} \mathrm{C}$ dengan rerata $72,79^{\circ} \mathrm{C}$ [10]. Penelitian [11] menggunakan biomassa sabut kelapa sebagai sumber energi dalam merancang alat pengering yaitu tungku terpisah dengan penukar kalor yang disusun dari berkas pipa paralel. Penelitian selanjutnya menggunakan sekam sebagai bahan bakar alat pengering dengan variasi jumlah pipa dan jarak antar lubang sirkulasi udara. Alat yang dibuat terdiri dari ruang pembakaran sekam, pipa penukar kalor dan lemari pengering. Hasil penelitian tersebut menunjukkan temperatur ruang pengering yang tertinggi dihasilkan pada tungku dengan jumlah pipa penukar kalor 9 buah dan jarak lubang sirkulasi udara $50 \mathrm{~mm}$. Semakin banyak pipa penukar kalor pada alat uji maka semakin luas permukaan kontak perpindahan panas yang terjadi di dalam tungku maupun di dalam ruang pengering. Semakin luas permukaan kontak perpindahan panas pada tungku menyebabkan semakin besar pula kalor hasil pembakaran sekam yang mampu diserap oleh pipapipa penukar kalor. Temperatur pipa penukar kalor sendiri dipengaruhi oleh proses pembakaran pada tungku. Pembakaran sekam dalam tungku memerlukan suplai udara yang berasal dari lubang yang terdapat pada dinding tungku, sehinggga jarak lubang sirkulasi pada tungku akan mempengaruhi proses pembakaran. Dua ratus menit pertama terjadi kenaikan temperatu pipa penukar kalor, karena pembakaran sekam dimulai dari dasar tungku tepat di atas pipa penukar kalor. Dengan bertambahnya waktu maka proses pembakaran akan merambat ke atas sampai semua bahan bakar sekam habis terbakar. Semakin jauh pembakaran sekam dari pipa penukar kalor maka temperatur pipa semakin turun [9].

\section{METODE PENELITIAN}

Penelitian ini merupakan penelitian eksperimental pengujian unjuk kerja alat pengering. Alat pengering terdiri dari tungku pembakaran sekam, lemari pengering, dan pipa penukar kalor. Tungku pembakaran merupakan ruang untuk proses pembakaran limbah sekam padi dengan lubang sirkulasi udara pada dindingnya, yang memiliki ukuran panjang $0,5 \mathrm{~m}$, lebar $0,5 \mathrm{~m}$, dan tinggi $0,8 \mathrm{~m}$ dengan kapasitas $20 \mathrm{~kg}$ sekam. Pipa penukar kalor berbahan black steel, berdiameter $2,54 \mathrm{~cm}$ dan ditempatkan $10 \mathrm{~cm}$ di atas lubang abu, karena karakteristik pembakaran sekam terjadi di dasar tumpukan sekam dan selanjutnya merambat ke atas. Penukar kalor terdiri dari pipa yang jumlah 9 buah yang disusun paralel dengan 1 (satu) lintasan aliran fluida yang berfungsi sebagai penghubung dan mentransfer panas dari ruang pembakaran ke lemari pengering. Ruang pengering memiliki ukuran panjang $0,5 \mathrm{~m}$, lebar $0,5 \mathrm{~m}$, dan tinggi $0,6 \mathrm{~m}$ yang dilengkapi kipas sebagai pengisap udara panas. Pengujian dilakukan untuk mengeringkan cabai besar. Skematik penelitian seperti disajikan pada 
Gambar 1. Data yang diukur meliputi temperatur pipa penukar kalor, ruang pengering, lingkungan, kecepatan aliran udara, waktu pembakaran sekam dan kadar air cabai.

Jumlah kalor (panas) yang digunakan untuk pengeringan dapat dihitung dengan menggunakan rumus berikut.

$$
\mathrm{Q}=\mathrm{Q}_{1}+\mathrm{Q}_{2}+\mathrm{Q}_{3}
$$

$Q_{2}=$ Panas sensibel air $(\mathrm{kJ})$

$Q_{3}=$ Panas laten penguapan air $(\mathrm{kJ})$

$\mathrm{Q}_{1}$ adalah panas sensible bahan yang dikeringkan yaitu jumlah panas yang digunakan untuk memanaskan bahan.

$$
\mathrm{Q}_{1}=\mathrm{m}_{\mathrm{k}} \mathrm{C}_{\mathrm{p}}\left(\mathrm{T}_{\mathrm{f}}-\mathrm{T}_{\mathrm{i}}\right)
$$

Keterangan:

$Q_{1}=$ Panas sensibel bahan $(\mathrm{kJ})$

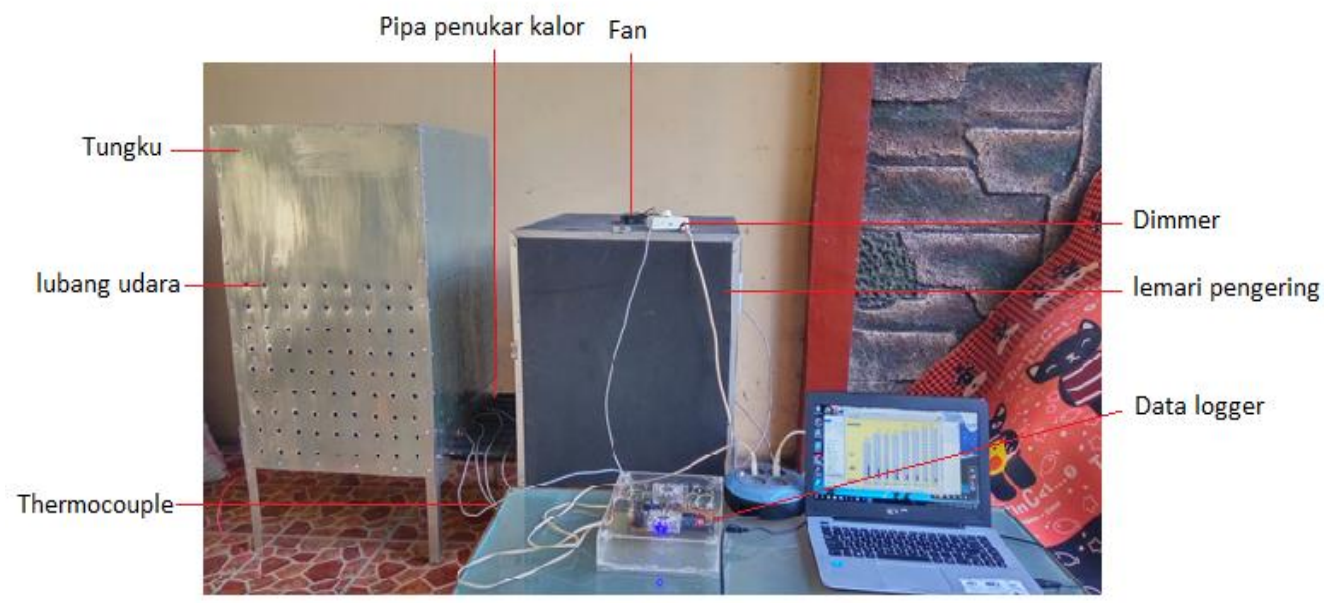

Gambar 1 Peralatan penelitian

Besarnya panas spesifik cabai adalah sebesar 3,81 kJ/kg ${ }^{\circ} \mathrm{C}$ [9]. $\mathrm{Q}_{2}$ adalah panas sensible air yaitu panas yang digunakan untuk menaikkan suhu air di dalam bahan.

$$
\mathrm{Q}_{2}=\mathrm{m}_{\mathrm{a}} \mathrm{C}_{\mathrm{pa}}\left(\mathrm{T}_{\mathrm{f}}-\mathrm{T}_{\mathrm{i}}\right)
$$

$\mathrm{Q}_{3}$ adalah panas laten penguapan air yaitu jumlah panas yang digunakan untuk menguapkan air bahan.

$$
\begin{aligned}
& \mathrm{Q}_{3}=\mathrm{m}_{\mathrm{a}} \mathrm{h}_{\mathrm{fg}} \ldots \ldots \ldots \ldots \ldots \ldots \ldots \\
& K_{a}=\left(\frac{M_{t}-M_{K}}{M_{t}}\right) 100 \%
\end{aligned}
$$

$\mathrm{m}_{\mathrm{k}}=$ massa kering bahan, $\mathrm{m}_{\mathrm{t}}=$ massa total, $\mathrm{C}_{\mathrm{p}}=$ panas jenis bahan, $\mathrm{T}_{\mathrm{f}}=$ Suhu akhir, $\mathrm{T}_{\mathrm{i}}=$ suhu awal, $\mathrm{K}_{\mathrm{a}}=$ kadar air, $\mathrm{m}_{\mathrm{a}}=$ massa air, $\mathrm{C}_{\mathrm{pa}}=$ panas jenis air, $\mathrm{h}_{\mathrm{fg}}$ $=$ panas laten penguapan air.

Energi masuk ke ruang pengering berasal dari udara yang membawa panas secara konveksi dari ruang pemanas. Volume udara yang masuk ke dalam alat pengering dapat dihitung menggunakan rumus sebagai berikut.

$$
\mathrm{V}=\dot{\forall} \times \mathrm{t}
$$

dengan $\dot{\forall}=$ debit udara masuk, $\mathrm{t}=$ waktu pengeringan.

Besarnya kalor yang diberikan oleh udara panas pada bahan yang dikeringkan digunakan rumus sebagai berikut.

$$
\mathrm{q}=\rho_{\mathrm{u}} \mathrm{V} \mathrm{C}_{\mathrm{pu}}\left(\mathrm{T}_{\mathrm{m}}-\mathrm{T}_{\mathrm{k}}\right)
$$

$\rho_{\mathrm{u}}=$ massa jenis udara, $\mathrm{C}_{p u}=$ panas jenis udara, $\mathrm{T}_{\mathrm{m}}=$ suhu rata-rata udara masuk pengering, $T_{k}=$ suhu ratarata udara keluar pengering.

Untuk efisiensi termal pada proses pengeringan dapat dihitung dengan persamaan berikut.

$$
\eta=\frac{\mathrm{Q}}{\mathrm{q}} \times 100 \%
$$




\section{HASIL DAN PEMBAHASAN}

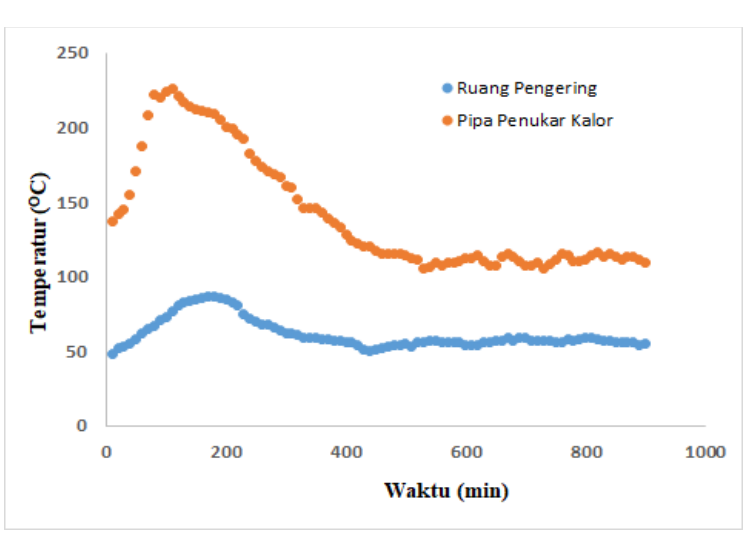

\section{Gambar 2 Waktu pengeringan vs temperatur pipa penukar kalor dan ruang pengering}

Gambar 2 menunjukkan bahwa besarnya temperatur ruangan pengering sangat dipengaruhi oleh temperatur pipa penukar kalor. Temperatur pipa penukar kalor sendiri dipengaruhi oleh proses pembakaran pada tungku. Pembakaran sekam dalam tungku memerlukan suplai udara yang berasal dari lubang yang terdapat pada dinding tungku. Dua ratus menit pertama terjadi kenaikan temperatur pipa penukar kalor, karena pembakaran sekam dimulai dari dasar tungku tepat di atas pipa penukar kalor. Dengan bertambahnya waktu maka proses pembakaran akan merambat ke atas sampai semua bahan bakar sekam habis terbakar. Semakin jauh pembakaran sekam dari pipa penukar kalor maka temperatur pipa semakin menurun. Selanjutnya temperatur ruangan dipertahankan dengan rentang temperatur $50-60^{\circ} \mathrm{C}$ dengan cara mengeluarkan abu dalam tungku pembakaran secara periodik. Temperatur ruang pengering sejalan dengan penelitian [12] bahwa cabai kering optimal pada suhu $60^{\circ} \mathrm{C}$ dengan pengujian dilakukan pada alat pengering.

Alat pengering digunakan untuk mengeringkan cabai yang memiliki berat awal cabai yang dikeringkan 1900 gram, dengan kadar air sebesar $85,8 \%$. Cabai tersebut diletakkan di dalam lemari pengering yang memiliki 4 buah rak pengering. Gambar 3 Memperlihatkan semakin lama waktu pengeringan menyebabkan berat cabai dan laju pengeringan semakin kecil. Setelah 15 jam pengujian berat cabai berkurang dari 1900 gram menjadi 646 gram atau sebesar $66 \%$. Rata-rata laju pengeringan diperoleh sebesar 1,395 gram/menit.

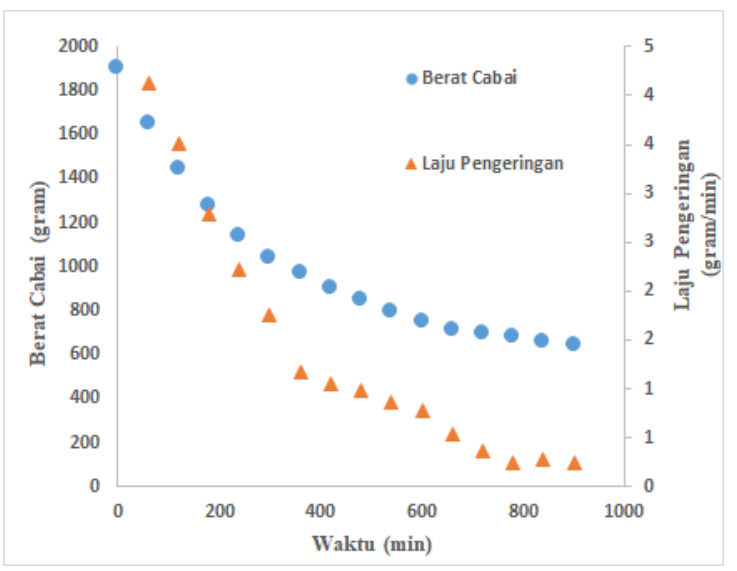

Gambar 3 Waktu pengeringan vs berat cabai dan laju pengeringan

Gambar 4. Menunjukkan penurunan kadar air selama waktu pengujian dari kadar air awal cabai $85,8 \%$ menjadi $58,2 \%$, atau terjadi penurunan kadar air sebesar $32 \%$ selama 15 jam pengujian. Hal ini menunjukkan semakin lama waktu pengeringan semakin banyak air yang teruapkan sehingga kadar air cabai menurun. Efisiensi rata-rata pengeringan yang diperoleh sebesar $22 \%$.

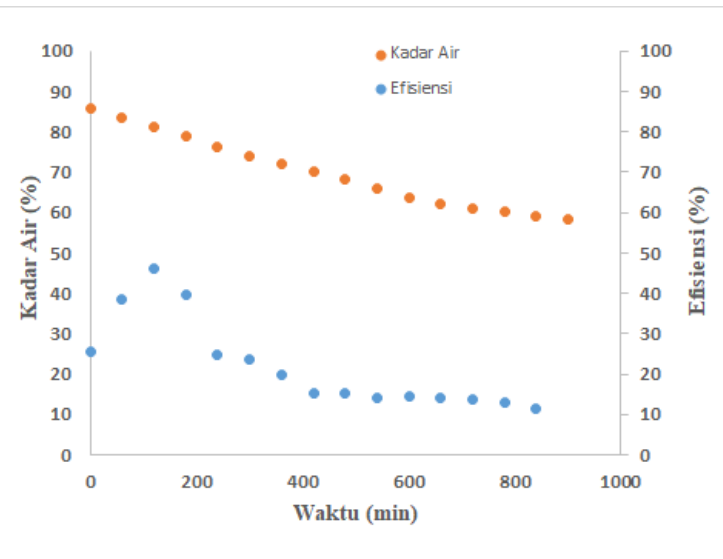

Gambar 4 Waktu pengeringan vs kadar air dan efisiensi pengering

\section{KESIMPULAN}

Hasil pengujian alat pengering menunjukkan berat bahan, kadar air, laju pengeringgan dan efisiensi pengering mengalami penurunan terhadap waktu. Besarnya temperatur lemari pengering dipengaruhi oleh besar kecilnya temperatur pipa penukar kalor. Temperatur lemari pengering berkisar $50-60^{\circ} \mathrm{C}$, dengan laju aliran udara 
$0,49 \mathrm{~m}^{3} /$ menit. Alat ini mampu menurunkan kadar air cabai $85,8 \%$ hingga $58,2 \%$ dalam rentang waktu 900 menit dengan efisiensi rata-rata sebesar $22 \%$.

\section{UCAPAN TERIMA KASIH}

Ucapan terima kasih dan penghargaan kami disampaikan kepada Kementerian riset, Teknologi, dan Pendidikan Tinggi sebagai institusi pemberi dana penelitian, dan Jurusan Teknik Mesin Unran yang telah memberikan fasilitas sehingga penelitian ini dapat terlaksana.

\section{DAFTAR PUSTAKA}

[1] Sontakke M.S. and Salve S.P., Solar Drying Technologies: A Review. International Refereed Journal of Engineering and Science, Vol. 4, Issue 4, 2015, pp. 29-35.

[2] Syahrul S., Romdhani R., dan Mirmanto, Pengaruh Variasi Kecepatan Udara dan Massa Bahan terhadap Waktu Pengeringan Jagung pada Alat Fluidized Bed. Dinamika Teknik Mesin: Jurnal Keilmuan dan Terapan Teknik Mesin, Vol. 6, No. 2, 2016, hal. 120-126.

[3] Suryadi, Sukmawaty, dan Putra G.M.D., Scale Up dan Uji Teknis Alat Pengering Tipe Fluidized Bed [Scale Up and Technical Test of Fluidized Bed Dryer. Jurnal Ilmiah Rekayasa Pertanian dan Biosistem, Vol. 5, No. 2, 2017, hal. 452-461.

[4] Mohanraj M. and Chandra S., Performance of A Force Convection Solar Drier Integrated with Gravel as Heat Storage Material for Chili Drying. Journal of Engineering Science and Technology, Vol. 4, Issue 3, 2009, pp. 305-314.

[5] Susana I G.B. dan Santosa I G., Peningkatan Produktivitas Perajin Ikan Teri dengan Konversi
Energi Biomassa. Jurnal Logic, Vol. 15, No. 1, 2015, hal. 47-50.

[6] Fudholi A., Othman M. Y., Ruslan M. H., and Sopian K., Drying of Malaysian Capsicum annuum L. (Red Chili) Dried by Open and Solar Drying. International Journal of Photoenergy, 2013.

[7] Alit I.B. dan Susana I G.B., Pengaruh Kecepatan Udara pada Alat Pengering Jagung dengan Mekanisme Penukar Kalor. Rekayasa Mesin, Vol. 11, No. 1, 2020, hal. 77-84.

[8] Fathurrahman, Syahrul, Nurchayati, Mirmanto, dan Sukmawaty, Pengaruh Temperatur dan Kecepatan Udara terhadap Laju Pengeringan Jagung pada Alat Fluidized Bed Dryer. Prosiding Seminar Nasional Mesin dan Industri (SNMI IX), Lombok, 2017.

[9] Susana I G. B., Yudhyadi I G.N.K., Alit I.B., Mirmanto, and Okariawan I D.K., Effect of Hole Spacing and Number of Pipe on Dryer Box Temperature. International Journal of Mechanical Engineering and Technology (IJMET), Vol. 8, Issue 11, 2017, pp. 1029-1035.

[10]Susana I.G.B., Mara I.M., Okariawan I.D.K., Alit I.B., \& Aryadi I.G.A.K.C.A.W., 2019, Ash Hole Variation in Rice Husk Biomass Furnace with Parallel Flow Heat Exchanger to Drying Box Temperature. ARPN Journal of Engineering and Applied Sciences, 14 (2), 583586.

[11] Susana I.G.B., Improve of Worker Performance and Quality of Anchovy with Ergonomic Hybrid Solar Dryer. Journal of Engineering and Applied Sciences, Vol. 13, Issue 5, 2018, pp. 1662-1667.

[12] Setiawan Y., Rodiawan, Wijianti E.S., dan Habibi N., Pengaruh Suhu dan Putaran Rak terhadap Laju Pengeringan Cabai Merah menggunakan Sumber Panas Heater. Machine: Jurnal Teknik Mesin, Vol. 3, No. 1, 2017, hal. 14. 